\title{
Efeito bactericida do gerador de alta frequência na cultura de Staphylococcus aureus
}

\author{
Bactericidal effect of high frequency generator in Staphylococcus aureus culture
}

Andiara Martins', Josiceli Telles da Silva', Laureane Graciola', Andersom Ricardo Fréz², João Afonso Ruaro 3 , Maria da Glória Karan Marquetti ${ }^{4}$

\begin{abstract}
RESUMO I O objetivo deste estudo foi verificar o efeito bactericida do gerador de alta frequência sobre a cultura de Staphylococcus aureus. Para isso, 36 placas de Petri inoculadas com Staphylococcus aureus foram divididas em 6 grupos, sendo 4 tratados (G5-15, G5-10, G3-15 e G3-10) e 2 controles (GC3 e GC5). O G5-15 e o G5-10 foram tratados 5 vezes por semana durante 15 e 10 minutos respectivamente, enquanto o G3-15 e o G3-10 foram tratados 3 vezes por semana durante 15 e 10 minutos respectivamente. No tratamento, foi utilizado o gerador de alta frequência na intensidade 10, técnica de faiscamento com eletrodo standard. Após o 150 dia de tratamento, foram realizadas repicagens para verificar se houve crescimento de novas culturas, observando-se que apenas o G5-15 mostrou-se eficaz quando comparado ao GC5 ( $p=0,0039$ ). Assim, o gerador de alta frequência apresentou efeito bactericida diante de cultura de Staphylococcus aureus in vitro em uma frequência de 5 vezes por semana aplicado por 15 minutos diários.
\end{abstract}

Descritores I modalidades de fisioterapia; Ozônio; crescimento bacteriano; Staphylococcus aureus.

\begin{abstract}
I The purpose of this study was to check the bactericidal effect of the high frequency generator over the Staphylococcus aureus culture. A total of 36 Petri dishes inoculated with Staphylococcus aureus were divided into 6 groups, including 4 treated (G5-15, G5-10, G3-15 and G3-10) and 2 controls (GC3 e GC5). G5-15 and G5-10 were treated 5 times per week during 15 and 10 minutes, respectively, while G3-15 and G3-10 were treated 3 times per week during 15 and 10 minutes, respectively. In treatment, it was used the high frequency generator with intensity of 10 , sparking technique with standard electrode. After the 15th day of treatment, there were performed transplanting, in order to check if there were growth of new cultures, and only G5-15 showed to be effective when compared to GC5 $(p=0.0039$ ). So, the high frequency generator had a bactericidal effect on Staphylococcus aureus in vitro culture at a frequency of 5 times per week and exposure time of 15 minutes daily.
\end{abstract}

Keywords I physical therapy modalities; ozone; bacterial growth; Staphylococcus aureus.

\footnotetext{
Estudo desenvolvido no Laboratório de Microbiologia da Faculdade Anglo-Americano (FAA) - Foz do Iguaçu (PR), Brasil. 'Fisioterapeutas pela Faculdade Anglo-Americano (FAA) - Foz do Iguaçu (PR), Brasil.

${ }^{2}$ Ms.; Professor do Departamento de Fisioterapia da Universidade Estadual do Centro-Oeste (UNICENTRO) - Guarapuava (PR), Brasil. ${ }^{3}$ Ms.; Professor da Universidade Federal do Rio Grande do Norte (UFRN)/Faculdade de Ciências da Saúde do Trairi (FACISA) - Santa Cruz (RN), Brasil.

${ }^{4}$ Professora Esp. da FAA - Foz do Iguaçu (PR), Brasil.
} 


\section{INTRODUÇÃO}

O gerador de alta frequência é um recurso que vem sendo utilizado na fisioterapia como auxílio no tratamento de lesões cutâneas. Apresenta efeito cicatrizante, térmico, analgésico e anti-inflamatório, os quais são importantes para o tratamento de lesões da pele. Demonstra também ação bactericida e antisséptica, sendo utilizado em lesões dermatológicas infectadas por bactérias e fungos ${ }^{1-3}$.

O gerador produz correntes alternadas que podem trabalhar com frequência entre 100.000 e $200.000 \mathrm{~Hz}$ e intensidade na ordem de $100 \mathrm{~mA}$. Além disso, o aparelho possui diferentes tipos de eletrodos de vidro, com gás ou ar rarefeito em seu interior que determinam a fluorescência. A função do gás é conduzir o fluxo da corrente, enquanto a fluorescência é causada pela passagem da corrente que ioniza as moléculas do gás. Em decorrência desse processo e da passagem de ondas eletromagnéticas pelo ar, há a formação de ozônio $\left(\mathrm{O}_{3}\right)$ na superfície do eletrodo ${ }^{1,4,5}$.

$\mathrm{O} \mathrm{O}_{3}$ estimula a produção de citocinas, ativa os linfócitos T, melhora a oxigenação e o metabolismo celular por meio da vasodilatação e produz um aumento da resposta enzimática antioxidativa, contribuindo, assim, de forma efetiva no tratamento de lesões cutâneas causadas por diferentes microrganismos ${ }^{1,6,7}$.

As bactérias são os organismos mais sensíveis ao $\mathrm{O}_{3}$, o que garante a sua eficácia bactericida. Ele atua primeiramente sobre a membrana bacteriana e causa a perda da atividade enzimática celular normal. A partir daí, ocorre uma mudança na permeabilidade da célula que leva à morte da bactéria. Esse processo ocorre associado à lise celular ${ }^{4}$.

O Staphylococcus aureus (S. aureus) é uma bactéria do grupo dos cocos gram-positivos, encontrada em pessoas saudáveis, principalmente na pele e nas fossas nasais. Porém, pode causar infecção em lesões cutâneas, além de infecções graves como pneumonia, meningite, endocardite, septicemia e até mesmo infecções sistêmicas, podendo levar à morte. $\mathrm{O} S$. aureus é responsável por $30 \%$ das infecções hospitalares e piogênicas ${ }^{8,9}$, e as infecções causadas por essa bactéria apresentam alto índice de morbidade e mortalidade tanto em casos hospitalares como domiciliares. É um microrganismo bastante resistente, que possui a característica de polimorfismo, o que dificulta o controle da infecção e faz com que os antibióticos antes utilizados para combatê-la hoje não sejam tão eficazes, dificultando o seu tratamento $^{10}$.
$\mathrm{O}$ aumento da resistência das bactérias às drogas antibióticas gera a necessidade de desenvolver novos meios bacteriostáticos e bactericidas que colaborem com a terapêutica de indivíduos infectados. No entanto, há poucos trabalhos que forneçam dados práticos sobre o efeito bactericida da alta frequência. Assim, o objetivo desse trabalho foi verificar se o gerador de alta frequência possui efeito bactericida em culturas de $S$. aureus.

\section{MATERIAIS E MÉTODOS}

Esta pesquisa, realizada no Laboratório de Microbiologia da Faculdade Anglo-Americano (Foz do Iguaçu,Paraná), caracteriza-se como um estudo analítico experimental in vitro, com uso do gerador de alta frequência em cultura de S. aureus.

\section{Cultura bacteriana}

Inicialmente, foi preparado Agar Manitol como meio de cultura, utilizando-se $111 \mathrm{~g}$ para $1.000 \mathrm{~mL}$ de água deionizada estéril. Os conteúdos foram colocados em um balão de bico chato devidamente fechado e dissolvidos no bico de Bunsen até alcançar o estado límpido. Em seguida, foram lacrados com papel craft e fita crepe indicadora, e levados à autoclave (Prismatec), até atingir $121^{\circ} \mathrm{C}$. Então a autoclave foi regulada em temperatura média, permanecendo por 15 minutos.

Após ser retirado da autoclave, o Agar, em estado líquido, foi distribuído em 36 placas de Petri, estéreis e descartáveis, de $5 \mathrm{~cm}$ de diâmetro. Essa distribuição ocorreu dentro de uma capela (Queimes) com luz ultravioleta previamente ligada por 30 minutos, para evitar contaminação. Depois de esfriar e atingir a forma sólida, as placas foram fechadas e colocadas em estufa (Odontobrás, modelo ECB 1.2 digital), por 24 horas, para se avaliar a esterilidade da placa.

Posteriormente, foi inoculada a bactéria $S$. aureus dentro da capela devidamente esterilizada. A inoculação foi realizada na forma estriada central, utilizando uma alça de 1 microlitro descartável estéril. A finalidade dessa forma de inoculação foi obter colônias isoladas para melhor abrangência da área tratada.

As placas de Petri permaneceram armazenadas na estufa a $35^{\circ} \mathrm{C}$, simulando a temperatura da pele, em um recipiente com gaze e água deionizada para manter o ambiente úmido. Após 48 horas da inoculação, as placas foram fotografadas e foi iniciado o tratamento proposto. 


\section{Procedimento experimental}

As 36 placas de Petri inoculadas com $S$. aureus foram divididas aleatoriamente em 6 grupos, ficando com 6 placas cada grupo.

Quatro grupos foram tratados (G5-15, G5-10, G3-15 e G3-10). O G5-15 e o G5-10 foram tratados 5 vezes por semana durante 15 e 10 minutos, respectivamente, enquanto o G3-15 e o G3-10, 3 vezes por semana durante 15 e 10 minutos, respectivamente. Todos os grupos tratados receberam 15 intervenções do uso do aparelho de alta frequência.

Dois grupos foram utilizados como controle (GC5 e GC3), não recebendo qualquer intervenção. O GC5 foi utilizado para acompanhar os grupos tratados cinco vezes na semana, enquanto o GC3 para os tratados três vezes na semana.

Para o procedimento de intervenção proposto, foi utilizado o aparelho gerador de alta frequência modelo Plus, fabricado pela empresa Tone Derm, com o eletrodo standard, com gás neon em seu interior, determinando uma fluorescência avermelhada. Aplicou-se a técnica de faiscamento, na qual o eletrodo é posicionado a milímetros de distância da placa, causando a formação de faíscas, com intensidade 10 (regulada no equipamento), a qual representa uma tensão de $100 \%$ para formação de $\mathrm{O}_{3}^{2}$.

Após a $15^{\mathrm{a}}$ aplicação do procedimento experimental, foram realizadas repicagens em novas placas estéreis, repetindo os procedimentos de esterilização. Essas repicagens tiveram a finalidade de verificar a proliferação das bactérias e, assim, observar o efeito do aparelho sobre as culturas. Após 48 horas, essas novas placas foram observadas e fotografadas para verificar a ocorrência de proliferação das bactérias.

\section{Análise dos resultados}

Para a análise, foi considerada a proliferação ou não de colônias de bactérias. Os dados foram agrupados aos pares e submetidos ao teste exato de Fisher do programa GraphPad InStat. Considerou-se o nível de significância de 5\% $(\mathrm{p}<0,05)$.

\section{RESULTADOS}

A Tabela 1 apresenta o número de placas que tiveram e que não tiveram proliferação de $S$. aureus de acordo com a frequência semanal e tempo da intervenção, além dos resultados dos grupos controle.

Quando comparados pares de grupos, observouse diferença significativa do uso do gerador de alta frequência em $S$. aureus apenas na relação entre o G5-15 com seu grupo controle (GC5). Nas demais comparações, nenhuma frequência semanal ou tempo de exposição mostrou-se significativa (Tabela 2).

\section{DISCUSSÃO}

Sabe-se que durante o uso do gerador de alta frequência existe a formação de $\mathrm{O}_{3}$ na superfície de seu eletrodo ${ }^{1,4,5}$. $\mathrm{O} \mathrm{O}_{3}$ tem sido utilizado para uma ampla gama de tratamentos, como em disfunções da coluna ${ }^{11}$, na prevenção de complicações pós-operatórias ${ }^{12,13}$, no estímulo do reaparo tecidual ${ }^{13,14}$ ou, ainda, como coadjuvante no tratamento de enfisema pulmonar ${ }^{15}$, sempre obtendo respostas positivas.

Há também que se relatar que o $\mathrm{O}_{3}$ pode ter efeitos nocivos, pois ainda não há tratamentos totalmente padronizados nem avaliados toxicologicamente ${ }^{16}$. Além disso, também não há consenso sobre a forma de aplicação do $\mathrm{O}_{3}$, pois se observa desde a aplicação direta do gás (ozonoterapia) ${ }^{14}$ o uso de água ozonizada ${ }^{7}$ ou a associação do $\mathrm{O}_{3}$ com óleos (óleo ozonizado) ${ }^{14}$.

Outrossim, o que tem sido observado como seu maior espectro de ação é o seu efeito bactericida e/ou fungicida, como revelaram os estudos de Białoszewski et al. ${ }^{17} \mathrm{e}$ Polydorou et al. ${ }^{18}$, inclusive associado ao oxigênio hiperbárico ${ }^{19}$. Entretanto, esse efeito ainda é pobremente ilustrado, principalmente quando o uso do $\mathrm{O}_{3}$ é atribuído ao uso do gerador de alta frequência, principal objetivo da presente pesquisa.

Nas pesquisas com seres humanos, o uso do gerador de alta frequência apresentou resultados satisfatórios em úlceras de pressão ${ }^{5}$. Também foi observada atividade

Tabela 1. Crescimento bacteriano por frequência semanal e tempo de intervenção

\begin{tabular}{|c|c|c|c|c|c|c|}
\hline & \multicolumn{3}{|c|}{10 minutos } & \multicolumn{3}{|c|}{15 minutos } \\
\hline & $3 x /$ semana & $5 x /$ semana & Controle & $3 x /$ semana & $5 x /$ semana & Controle \\
\hline $\begin{array}{l}\text { Número de placas } \\
\text { com proliferação }\end{array}$ & 2 & 4 & 6 & 3 & O & 6 \\
\hline $\begin{array}{l}\text { Número de placas } \\
\text { sem proliferação }\end{array}$ & 4 & 2 & 0 & 3 & 6 & 0 \\
\hline
\end{tabular}


Tabela 2. Diferença na proliferação de S. aureus entre pares de grupos

$\begin{array}{lc}\text { Grupos } & \text { Valor p } \\ \text { G5-15 X GC5 } & 0,0022^{*} \\ \text { G5-10 X GC5 } & 0,4545 \\ \text { G3-15 X GC3 } & 0,1818 \\ \text { G3-10 X GC3 } & 0,0606 \\ \text { G5-15 X G5-10 } & 0,0606 \\ \text { G3-15 X G3-10 } & 1,0000 \\ \text { G5-15 X G3-15 } & 0,1818 \\ \text { G5-10 X G3-10 } & 0,5671\end{array}$

*Significativo.

fungicida como tratamento complementar aos fármacos convencionais para tratamento das onicomicoses ${ }^{20}$ e para tratamento de verruga ungueal ${ }^{4}$. Para verruga ungueal, foi aplicado um protocolo de 3 intervenções diárias, de 15 minutos cada, durante 3 meses $^{4}$, enquanto para as onicomicoses o tratamento foi por 12 meses, mas sem descrição do protocolo ${ }^{20}$.

Já nas pesquisas com modelos animais, o estudo com o gerador de alta frequência demonstrou ser efetivo na reparação de feridas cutâneas em modelos experimentais em ratos, quando aplicado com uma intensidade de $80 \%$, por 120 segundos, durante 7 dias $^{21}$. Com o uso direto do $\mathrm{O}_{3}$, um estudo experimental com coelhos demonstrou seu efeito bactericida, diminuindo a reação inflamatória pela redução da carga bacteriana da endoftalmite causada por S. epidermidis após aplicação intravítrea de solução salina ozonizada ${ }^{22}$.

Outro estudo que demonstrou o efeito bactericida do $\mathrm{O}_{3}$ descreveu o uso desse gás como agente para desinfecção de água, o qual agiu sobre bactérias, fungos e vírus, além de ter reduzido totalmente a proliferação de S. aureus ${ }^{7}$, o que está de acordo parcial com os resultados do presente estudo.

Além desse, em um modelo experimental in vitro, para avaliar o efeito de gases sobre o crescimento bacteriano, o $\mathrm{O}_{3}$ demonstrou-se superior para inibir esse crescimento quando comparado a outros gases ${ }^{23}$.

Seu efeito fungicida in vitro pode ser observado em cultura de Candida tropicalis, as quais foram submetidas a uma exposição da alta frequência com a técnica de faiscamento, utilizando o mesmo modelo do equipamento gerador da presente pesquisa, mas com intensidade 8 . Os autores observaram uma inibição no crescimento em $90 \%$ das placas quando expostas 5 minutos por dia $^{1}$. Entretanto, esses resultados não permitem a comparação com a presente pesquisa, pois os microrganismos utilizados foram distintos.

$\mathrm{Na}$ literatura, os resultados sobre o uso do gerador de alta frequência e do ozônio limitam-se aos estudos in vitro ou com modelos experimentais ou estudos de caso. Entretanto, pode-se observar que, quando se trata de estudos in vitro, esses resultados aparecem em poucas e até mesmo em uma única intervenção ${ }^{1,22,23}$, enquanto em seres humanos, principalmente nas lesões fúngicas, são necessários meses de aplicação ${ }^{4,20}$.

$\mathrm{Na}$ presente pesquisa, o único grupo que apresentou resultado bactericida significativo foi o grupo G5-15. Tal fato pode ser justificado por este ser o grupo que recebeu a intervenção com menor intervalo entre as abordagens associada ao maior tempo diário de aplicação. Porém, outro fator observado posteriormente, no único trabalho que aplicou o gerador de alta frequência in vitro ${ }^{1}$, foi o uso de uma folha de papel alumínio abaixo da placa de Petri durante a aplicação do gerador de alta frequência. Segundo os autores ${ }^{1}$, o uso do papel alumínio melhora a condutibilidade, já que o vidro não é um bom condutor elétrico, assemelhando-se, assim, à pele.

Assim, apesar de observarem-se resultados positivos no uso do gerador de alta frequência in vitro, é necessário ter cautela ao transferirem-se resultados obtidos em laboratório para situações clínicas. Portanto, estudos in vivo devem ser realizados para ter-se a certeza da recomendação desse recurso como método de tratamento na fisioterapia com o objetivo antimicrobiano.

\section{CONCLUSÕES}

O aparelho de alta frequência apresentou efeito bactericida em cultura de $S$. aureus in vitro após 15 intervenções, em uma frequência semanal de 5 aplicações, com tempo de exposição diária de 15 minutos.

Em virtude dos resultados animadores e do baixo número de pesquisas sobre o uso clínico da alta frequência, sugerem-se novas pesquisas, com possibilidade de utilizarem-se outros microrganismos, diferentes tempos e frequência de aplicação.

\section{REFERÊNCIAS}

1. Higa DR, Cese PC, Falcão RMM, Cese AC, Chang MR, Borges FS, et al. Efeito do gerador de alta frequência sobre cultura de Candida tropicalis. Rev Esp Fisioter. 2007;1(1):22-6.

2. Campos MSMP. Manual do aparelho HVG Compact. KW Indústria Nacional de Tecnologia Eletronica Ltda.- EPP. Revisão 09/2005. 
3. Oliveira LMN. Utilização do ozônio através do aparelho de alta frequência no tratamento da úlcera de pressão. Rev Bras Ciênc Saúde. 2011;9(30):41-6

4. Barros VCC, Santos VNS, Santos FB. Tratamento de verruga ungueal causada por HPV com uso do gerador de alta frequência: relato de caso. Rev Esp Fisioter. 2007:1(2):33-5.

5. Borges FS, Borges FBS. Alta frequência. In: Borges FS. Modalidades terapêuticas nas disfunções estéticas. São Paulo: Phorte; 2006

6. Almeida E, Assalin MR, Rosa MA, Durán N. Tratamento de efluentes industriais por processos oxidativos na presença de ozônio. Quím Nova. 2004:27(5):818-24.

7. Velano HE, Nascimento LC, Barros LM, Panzeri H. Avaliação in vitro da atividade antibacteriana da água ozonizada frente ao Staphylococcus aureus. Pesq Odontol Bras. 2001;15(1):18-22.

8. Santos AL, Santos DV, Freitas CC, Ferreira BLA, Afonso LF, Rodrigues CR, et al. Staphylococcus aureus: visitando uma cepa de importância hospitalar. J Bras Patol Med Lab. 2007:43(6):413-23.

9. Mundim GJ, Dezena RA, Oliveira ACS, Silva PR, Cardoso M, Pereira GA, et al. Avaliação da presença de Staphylococcus aureus nos leitos do Centro de Terapia Intensiva do Hospital Escola da Faculdade de Medicina do Triângulo Mineiro, em relação à posição no colchão antes e após a limpeza. Rev Soc Bras Med Trop. 2003;36(6):685-8.

10. Fagundes H, Oliveira CAF. Infecções intramamárias causadas por Staphylococcus aureus e suas implicações em saúde pública. Ciência Rural. 2004;34(4):1315-20.

11. Andreula C. Ozone therapy. Neuroradiology. 2011;53(Suppl 1):207-9.

12. Mustafaev EM, Martov AG, Naumov AG, Siniukhin VN, Shakir F, Merinov DS, et al. The role of ozone therapy in prevention of pyoinflammatory complications after transurethral resection of prostatic adenoma. Urologia. 2007;(1):18-23,27.

13. Vescovi P, Nammour S. Bisphosphonate-raleted osteonecrosis of the jaw (BRONJ) therapy. A critical review. Minerva Stomatol. 2010;59(4):181-203, 204-13.
14. Cardoso CC, Dias Filho E, Pichara NL, Campos EGC, Pereira MA, Fiorini JE. Ozonoterapia como tratamento adjuvante na ferida do pé diabético. Rev Méd Minas Gerais. 2010;20(n.esp):442-5.

15. Calunga FJL, Paz AY, Menéndez CS, Martínez A, Hernández A. Rectal ozone therapy for patients with pulmonary emphysema. Rev Med Chil. 2011;139(4):439-47.

16. Bocci V, Zanardi I, Travagli V. Oxygen/ozone as a medical gas mixture. A critical evaluation of the various methods clarifies positive and negative aspects. Med Gas Res. 2011;(1):6.

17. Białoszewski D, Bocian E, Bukowska B, Czajkowska M, SokółLeszczyńska B, Tyski S. Antimicrobial activity of ozonated water. Med Sci Monit. 2010;16(9):MT71-5.

18. Polydorou O, Halili A, Wittmer A, Pelz K, Hahn P. The antibacterial effect of gas ozone after 2 months of in vitro evaluation. Clin Oral Investig. 2012:16(2):545-50.

19. Oguz E, Ekinci S, Eroglu M, Bilgic S, Koca K, Durusu M, et al. Evaluation and comparison of the effects of hyperbaric oxygen and ozonized oxygen as adjuvant treatments in an experimental osteomyelitis model. J Surg Res. 2011;171(1):e61-8.

20. Silva JLM, Doimo G, Faria DP. Uso de ondas de alta frequência no tratamento de onicomicose - comunicação preliminar de três casos. An Bras Dermatol. 2011;86(3):598-600.

21. Sá HP, Nunes HM, Santo LAE, Oliveira Júnior GC, Silva JMN, Carvalho KC, et al. Estudo comparativo da ação do laser GaAllnP e do gerador de alta frequência no tratamento de feridas cutâneas em ratos: estudo experimental. ConScientiae Saude. 2010;9(3):360-6.

22. Lake JC, Felberg S, Malavazzi GR, Goulart DA, Nishiwaki-Dantas MC, Dantas PEC. Efeito terapêutico da aplicação intra-ocular de ozônio em modelo experimental de endoftalmite por Staphylococcus epidermidis em coelhos. Arq Bras Oftalmol. 2004;67(4):575-9.

23. Pereira MMS, Navarini A, Mimica LMJ, Junior AMP, Silva RA. Efeito de diferentes gases sobre o crescimento bacteriano. Estudo experimental "in vitro". Rev Col Bras Cir. 2005;32(1):12-4. 